ONLINE MUTATION REPORT

\title{
Clinical and genetic characteristics of $\alpha$ cardiac actin gene mutations in hypertrophic cardiomyopathy
}

\author{
J Mogensen, A Perrot, P S Andersen, O Havndrup, I C Klausen, M Christiansen, P Bross, \\ H Egeblad, H Bundgaard, K J Osterziel, G Haltern, H Lapp, P Reinecke, N Gregersen, A D Børglum
}

J Med Genet 2004;41:e10 (http://www.jmedgenet.com/cgi/content/full/41/1/e10)

$\mathrm{H}$ ypertrophic cardiomyopathy (HCM) is a dominantly inherited disease defined by unexplained myocardial hypertrophy. The prevalence is about $0.2 \%$ in the general population. The condition is characterised by a heterogeneous disease expression, and common symptoms include angina, dyspnoea, palpitations, syncope, and exercise limitation. Hypertrophic cardiomyopathy is a frequent cause of sudden cardiac death in young people. ${ }^{1}$ More than 200 mutations associated with the disease have been identified in sarcomeric contractile protein genes: TNNT2 (troponin T), MYL3 (essential myosin light chain), MYBPC3 (myosin binding protein $\mathrm{C}$ ), MYL2 (regulatory myosin light chain), MYH7 ( $\beta$ myosin heavy chain), TPMI ( $\alpha$ tropomyosin), ACTC ( $\alpha$ cardiac actin), and TNNI3 (troponin I). ${ }^{2-4}$

In addition, mutations recently have been reported in two non-sarcomeric genes. ${ }^{5-7}$

Mutations in ACTC have also been reported to cause the inherited form of idiopathic dilated cardiomyopathy (DCM). It has been suggested previously that ACTC mutations that affect sarcomere contraction lead to HCM, whereas ACTC mutations that affect force transmission from the sarcomere to the surrounding syncytium lead to DCM. ${ }^{38}$

We report the clinical and genetic characteristics of ACTC mutations in 206 consecutive patients with HCM.

\section{MATERIALS AND METHODS}

Informed consent was obtained from each participant in accordance with local institutional review committee guidelines.

We investigated 206 consecutive Caucasian probands with HCM from Germany $(n=146)$ or Denmark $(n=60)$ by mutation analysis of ACTC. We physically and genetically investigated relatives of probands who carried ACTC mutations. The diagnosis of HCM was based on the presence of unexplained myocardial hypertrophy. ${ }^{3}{ }^{10}$ In brief, a person was defined as having HCM if the maximal left ventricular wall thickness by echocardiography or cardiac magnetic resonance scan was $\geqslant 13 \mathrm{~mm}$ or the electrocardiogram (ECG) showed major Q wave abnormalities, left ventricular hypertrophy, or marked repolarisation alterations. One patient (pedigree B, participant I-1) was diagnosed with HCM on the basis of results obtained by cardiac catheterisation and cardiac magnetic resonance scans. Participants were suspected of having HCM if their ECG showed incomplete bundle branch block and right axis deviation (pedigree $\mathrm{A}$, participants III-2 and II-3). We classified the phenotype of all participants before DNA analysis.

We isolated genomic DNA from all participants, including controls, from peripheral blood samples, and we amplified ACTC by polymerase chain reaction (PCR) with intronic primers, as previously described. ${ }^{3}$ We analysed PCR products by single strand conformation polymorphism (SSCP) and heteroduplex analysis of exons 2,3 , and 4 with a precast $12.5 \%$ polyacrylamide gel at $4{ }^{\circ} \mathrm{C}$ and $20^{\circ} \mathrm{C}$ (Multiphor gel

\section{Key points}

- The study aimed to investigate the prevalence and clinical characteristics of $\alpha$ cardiac actin mutations (ACTC) in 206 consecutive families with hypertrophic cardiomyopathy (HCM) Mutation analysis was performed by SSCP analysis and direct sequencing. In addition, the likely impact of ACTC mutations on sarcomeric function was investigated by analysis of the crystal structure of the actin protein

- The prevalence of ACTC mutations was 1.5\%. Two novel mutations were identified. Available phenotypic information in carriers of ACTC mutations suggested a heterogeneous clinical appearance that ranged from unaffected cases to patients with severe disease presentation

- Examination of the crystal structure of actin showed that amino acids mutated in HCM were exposed to the surface domain of actin that interacts with myosin

- ACTC mutations are rare in HCM, and no specific genotype-phenotype correlation is apparent. The localisation of ACTC mutations in conserved and functional important regions of the gene substantiate the current hypothesis that ACTC mutations in HCM affect sarcomeric contraction, whereas ACTC mutations in dilated cardiomyopathy affect force transmission

apparatus; Pharmacia Biotech, Uppsala, Sweden). We visualised bands with silver staining and analysed abnormal conformers by direct sequencing. ${ }^{11}$ Because of difficulties in obtaining reproducible SSCP analysis of exons 1, 5, and 6, we subjected these exons to direct sequencing with standard protocols. We established the haplotypes of families A and B with analysis of a highly polymorphic short tandem repeat localised within ACTC. ${ }^{3}$ We performed Msl I restriction enzyme cleavage of DNA from family A according to the manufacturer's manual (New England Biolabs, Beverly, MA, USA).

\section{RESULTS}

\section{Genetic investigations}

The proband of family A (individual II- 1 ) had an 1153A $\rightarrow$ G nucleotide substitution in exon 3 , which resulted in a Tyr166Cys amino acid exchange. Subsequent mutation analysis of this proband's relatives identified three additional carriers of the mutated allele (fig 1 and table 1 ).

The proband of family B (individual I-1) had a $283 \mathrm{~A} \rightarrow \mathrm{C}$ nucleotide substitution in exon 5, which resulted in a Met305Leu amino acid substitution (fig 1 and table 1). The 


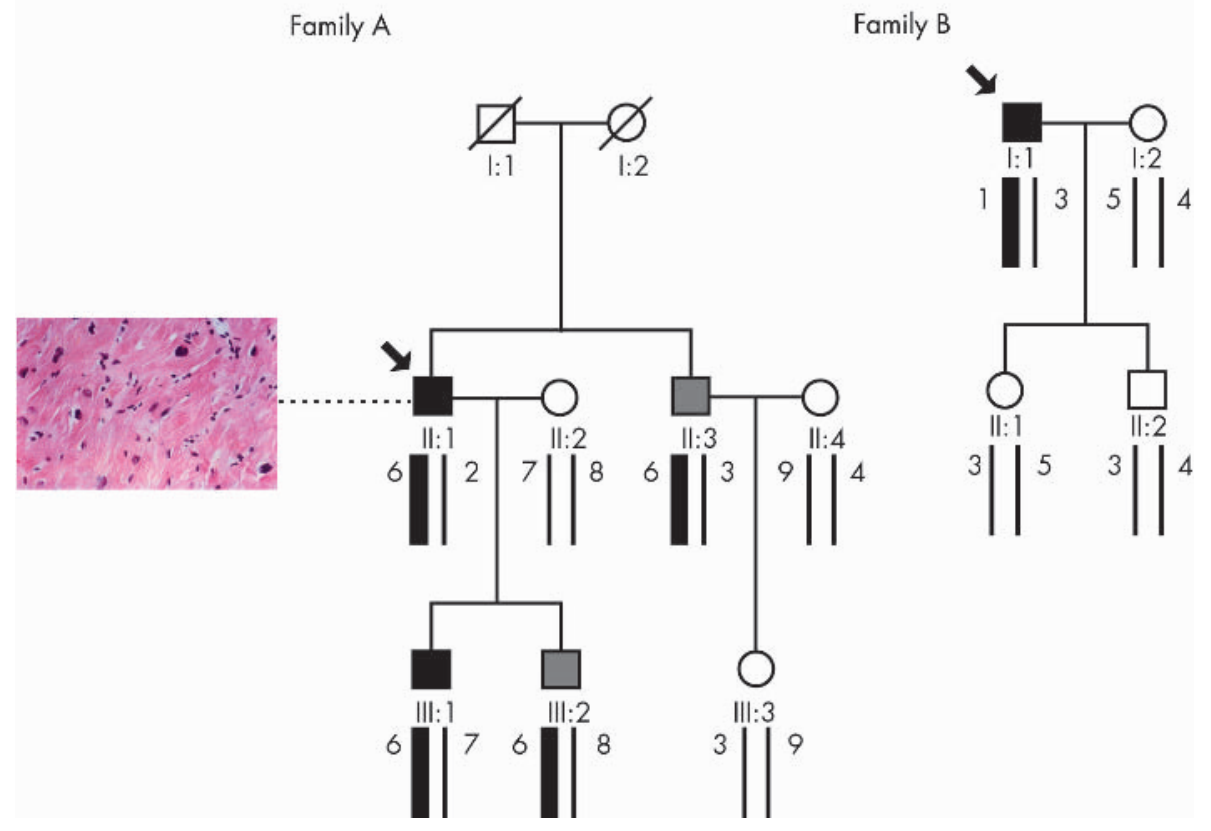

Figure 1 Pedigree drawing of families A and B, who carried ACTC Tyr166Cys and Met305Cys amino acid substitutions, respectively. The tissue section shown was part of the intraventricular septum removed by transaortical myectomy from individual II- 1 of family $A$ and stained with haematoxylin and eosin. The histology showed myocyte hypertrophy and disarray consistent with a diagnosis of HCM..$^{15}$ Alleles defined by the short tandem repeat polymorphism within ACTC shown in roman numbers. $\square$ men without $\mathrm{HCM}$; men who fulfilled diagnostic criteria for $\mathrm{HCM}$; men suspected of having HCM; $\bigcirc$, healthy women; / deceased; I normal genotype of ACTC, ACTC mutation that segregates with allele 6 in family A and allele 1 in family $B$.

presence of the mutation in proband $\mathrm{B}$ was confirmed by a Msll restriction enzyme assay, which cleaved the wildtype allele, as expected, and left the mutated allele intact. To diminish the possibility that the ACTC mutations identified (Tyr 166Cys and Met305Leu) were common polymorphisms, 150 control chromosomes were investigated by SSCP analysis (exon 3) or direct sequencing (exon 5). No sequence variations were identified, which confirmed the result of previous SSCP analyses of controls of exon 3 (300 chromosomes) and exon 5 (870 chromosomes). ${ }^{8}$ These observations are in accordance with the fact that cardiac actin is a highly conserved protein throughout evolution including the Tyrl66 and Met305 amino acids that are conserved in the 37 vertebrate and invertebrate actins that are part of the protein alignment database. ${ }^{12}$ Compared with the original sequence published more than a decade ago, five silent homozygous base changes were seen in all 206 individuals investigated (exon 2, 274T $\rightarrow$ G; intron 3, 1089G $\rightarrow$ C; exon 4, 1488T $\rightarrow$ C and $1532 \mathrm{C} \rightarrow \mathrm{T}$; and exon $6,284 \mathrm{~T} \rightarrow \mathrm{C}$ ), which is likely to reflect the contemporary, more accurate method of sequencing. Others have performed mutation analysis of ACTC in the context of DCM and identified a total of eight silent single nucleotide polymorphisms in populations of Asian and South African origin, respectively. ${ }^{13}{ }^{14}$

Table 1 Clinical features of families A and B

\begin{tabular}{|c|c|c|c|c|c|c|c|}
\hline Pedigree & $\begin{array}{l}\text { Age } \\
\text { (years) }\end{array}$ & Sex & Symptoms & Electrocardiogram findings & Echocardiogram findings & $\begin{array}{l}\text { Phenotypic } \\
\text { assignment }\end{array}$ & ACTC genotype \\
\hline \multicolumn{8}{|l|}{$A$} \\
\hline$\|-1$ & 51 & Man & $\begin{array}{l}\text { Angina } \\
\text { Dyspnoea (New York } \\
\text { Heart Association } \\
\text { grade III) }\end{array}$ & Atrial fibrillation & $\begin{array}{l}\text { HCM } \\
\text { Septum } 18 \mathrm{~mm} \\
\text { Systolic anterior movement } \\
\text { of mitral valve } \\
\text { Left ventricle outflow tract } \\
\text { gradient at rest } 35 \mathrm{~mm} \mathrm{Hg}\end{array}$ & $\mathrm{HCM}$ & Tyr166Cys \\
\hline III-1 & 27 & Man & No & $\begin{array}{l}\text { Incomplete right bundle } \\
\text { branch block }\end{array}$ & $\mathrm{HCM}$ & $\mathrm{HCM}$ & Tyr166Cys \\
\hline III-2 & 24 & Man & No & $\begin{array}{l}\text { Incomplete right bundle } \\
\text { branch block and right } \\
\text { axis deviation }\end{array}$ & $\begin{array}{l}\text { Septum } 15 \mathrm{~mm} \\
\text { Normal }\end{array}$ & Suspected HCM & Tyr166Cys \\
\hline $11-3$ & 47 & Man & No & $\begin{array}{l}\text { Incomplete right bundle } \\
\text { branch block and right } \\
\text { axis deviation }\end{array}$ & Normal & Suspected HCM & Tyr166Cys \\
\hline \multicolumn{8}{|c|}{ 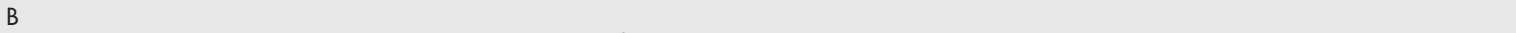 } \\
\hline $1-1$ & 61 & Man & $\begin{array}{l}\text { Angina } \\
\text { Dyspnoea (New York } \\
\text { Heart Association } \\
\text { grade II) }\end{array}$ & Atrial fibrillation & Not obtainable* & $\mathrm{HCM}$ & Met305Leu \\
\hline
\end{tabular}




\section{Clinical investigations}

The proband of family A was diagnosed with HCM at the age of 51 years. He had severe symptoms of angina and dyspnoea (New York Heart Association (NYHA) class III) (fig 1, table 1). An echocardiogram showed septal hypertrophy of $18 \mathrm{~mm}$, mild mitral regurgitation, systolic anterior movement of the mitral valve, and a left ventricle outflow tract gradient of $35 \mathrm{~mm} \mathrm{Hg}$ at rest, which increased to $60 \mathrm{~mm} \mathrm{Hg}$ after the Valsalva manoeuvre. Transaortal myectomy abolished the outflow tract obstruction and gave considerable symptomatic improvement. Part of the left ventricular septum was removed by transaortal myectomy and stained with haematoxylin and eosin. Histology of the removed myocardium showed myocyte hypertrophy and myofibrillar disarray consistent with a diagnosis of $\mathrm{HCM}^{15}$ (fig l). The proband's mother, individual I-2, had dyspnoea on exertion, which had started in her late twenties. She later developed atrial fibrillation and mitral regurgitation and died of congestive heart failure at the age of 50 years. The remaining relatives had no symptoms of disease, but the echocardiogram of participant III-1 showed septal hypertrophy of $15 \mathrm{~mm}$. In addition, the electrocardiograms of participants III-2 and II-3 had minor abnormalities in terms of incomplete right bundle branch block and right axis deviation, while their echocardiograms were within the upper normal range of the maximal left ventricular wall thickness (both $12 \mathrm{~mm}$ ).

The proband of family $\mathrm{B}$ was diagnosed at the age of 61 years. He had symptoms of angina on exertion and dyspnoea (NYHA II) (fig 1, table 1). Images of the heart by echocardiography were unobtainable, but cardiac catheterisation showed apical systolic obliteration of the left ventricle consistent with a diagnosis of apical HCM. This finding was confirmed by a cardiac magnetic resonance scan, which showed a maximal left ventricular wall thickness of $14 \mathrm{~mm}$. He had no family history of cardiac disease, and subsequent physical examination and mutation analysis of his children did not identify additional disease carriers.

\section{Analysis of actin crystal structure}

Actins are major constituents of the thin filaments in the muscle sarcomere. They generate force within the sarcomere in companion with myosin and transmit force from the sarcomere to the surrounding syncytium by the thin filament. Previous studies of ACTC mutations in families with either HCM or the hereditary form of DCM has led to the hypothesis that ACTC mutations in force generating domains lead to HCM, while ACTC mutations in force transmitting domains lead to DCM. ${ }^{3}$ This hypothesis has been further supported by analysis of a transgenetically modified mouse carrying ACTC mutations in both force transmitting and force generating domains, as the hearts of these mice had features of both HCM and DCM. ${ }^{16}$

Analysis of the ultrastructure of the actin molecule showed that the novel (Tyrl66, Met305) and previously reported (Ala295) actin amino acids mutated in HCM were situated around the five stranded $\beta$ sheet in the lower part of subdomain 3 of the actin molecule ${ }^{16}$ (fig 2 ). The side chains of all three amino acids are exposed to the surface that interacts with myosin and situated in close proximity to residues directly involved in interaction with myosin. ${ }^{17}$ The mutations lead to replacement of a polar side chain with a hydrophobic side chain or vice versa (Met305Leu and Ala295Ser) and the removal of an aromatic ring (Tyr 166Cys) that may distort the adjacent surface area. This may well influence the surface that interacts with myosin and thereby impair force generation. In addition, Tyrl66 is involved in the interactions between actin monomers, and Met305 forms part of the hydrophobic binding pocket for the adenosine moiety of the associated ATP and ADP. ${ }^{18}$ Monomeric actin binds ATP and

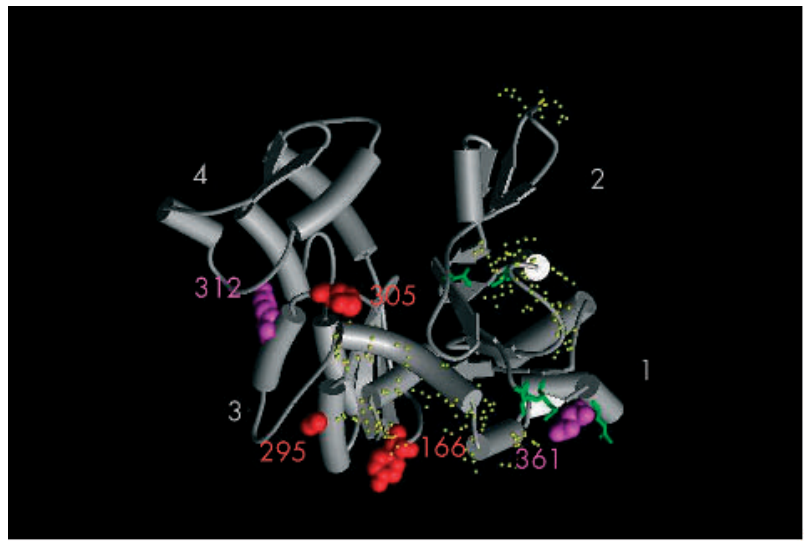

Figure 2 Schematic representation of actin monomer based on the crystal structure of the actin, prepared with WebLab ViewerLite (Molecular Simulations, San Diego, CA, USA) ${ }^{18}$ Putative binding sites to myosin are shown in yellow. ${ }^{19}$ The Tyr 166 and Met305 amino acid mutated in families $A$ and $B$, as well as the Ala295 previously reported to be mutated in HCM, shown in red. All HCM mutations are localised at the actin surface that interacts with myosin. Two amino acids previously reported to cause DCM (Arg312 and Glu361) are shown in purple. ${ }^{8}$ Amino acid differences between $\alpha$ cardiac actin and $\gamma$ enteric actin expressed in a transgenic ACTC knock out mouse highlighted in green. ${ }^{16}$

assembles into fibres after ATP-ADP hydrolysis. Disturbances of the nucleotide binding pocket or the actin-actin interchain interactions are likely to impair fibre assembly, which could result in disorganisation of the actin fibres and thus further decrease force generation within the sarcomere.

\section{DISCUSSION}

We identified two novel and one previously reported ACTC mutation in 3/206 (1.5\%) Caucasian HCM patients of Northern European origin. ${ }^{3}$ The rare finding of ACTC mutations was consistent with previous reports that identified three mutations in 368 patients with HCM and no mutations in 421 patients with HCM..$^{20-22}$

Conventional page gel SSCP analysis was used for mutation analysis of three exons of ACTC. This method is presumed to be less sensitive than direct sequencing and more recent methods developed for mutation screening. ${ }^{22}$ The frequency of ACTC mutations in our study, however, was similar to that in other studies, and it is unlikely therefore, that the SSCP method we used missed a significant number of mutations. Although the number of affected participants was limited in this study, the two amino acid substitutions identified (Tyr166Cys and Met305Leu) were believed to be disease causing mutations, because all clinically affected individuals were mutation carriers, no sequence variations were identified in ethnically matched control individuals, both mutations changed highly conserved amino acids, and both mutations were likely to change protein-protein interactions on the basis of analysis of the crystal structure of actin.

The phenotypes associated with the Tyrl66Cys and Met305Leu amino acid substitutions seemed to be heterogeneous. Both probands of families A and B had reduced exercise capacity and symptoms of disease in contrast with the remaining asymptomatic mutation carriers of family A. In addition, the proband of family A had pronounced hypertrophy of the septum that needed myectomy compared with the mild or absent hypertrophy of the remaining participants who carried the mutated allele.

The clinical findings associated with ACTC mutations described in previous studies further strengthen the impression of variable disease expression (table 2 ). The first study to 
Table 2 Clinical profile associated with previous reported ACTC mutations

\begin{tabular}{|c|c|c|c|c|c|c|}
\hline \multirow[b]{2}{*}{ Mutation } & \multirow[b]{2}{*}{$\begin{array}{l}\text { Carriers of } \\
\text { mutations }\end{array}$} & \multicolumn{5}{|l|}{ Patients } \\
\hline & & $\begin{array}{l}\text { Phenotype } \\
\text { positive }\end{array}$ & Symptomatic & $\begin{array}{l}\text { Abnormal } \\
\text { electrocardiogram }\end{array}$ & $\begin{array}{l}\text { Ventricular } \\
\text { arrhythmia }\end{array}$ & $\begin{array}{l}\text { Abnormal } \\
\text { echocardiogram }\end{array}$ \\
\hline Ala295Ser ${ }^{3}$ & 14 & 13 & 3 & 13 & $1^{*}$ & $9^{* *}$ \\
\hline Prol 64Ala ${ }^{20}$ & 1 & 1 & 1 & 1 & $1 \dagger$ & $1+\dagger$ \\
\hline Ala331Pro $^{20}$ & 1 & 1 & 1 & 1 & 0 & $1+\dagger$ \\
\hline Glu99lys ${ }^{20}$ & 7 & 6 & 6 & 7 & $2 \ddagger$ & 6‡士 \\
\hline \multicolumn{7}{|c|}{ 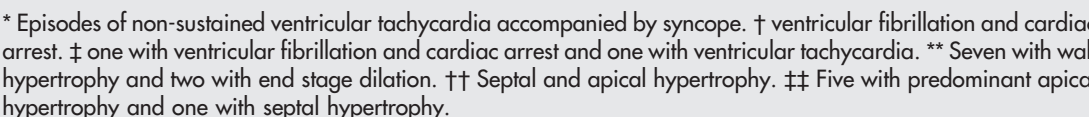 } \\
\hline
\end{tabular}

report on ACTC mutations identified an Ala295Ser amino acid substitution in a large Danish pedigree. ${ }^{3}$ Only a few of the affected people had symptoms of disease, including two with end stage dilated HCM and one with tachycardia caused by a Wolff-Parkinson-White syndrome, which preceded a later development of ventricular hypertrophy. The remaining carriers of the mutation, except one, fulfilled the diagnostic criteria for HCM, but none had symptoms of disease. The Ala295Ser mutation seemed to be associated with a high penetrance, diverse phenotypes, a relatively low morbidity, and no sudden deaths. These findings were different from those reported recently by Olson et al. ${ }^{19}$ They identified three novel ACTC mutations, of which two occurred de novo and one appeared in a family with seven disease carriers (table 2). Both de novo mutations were associated with early onset and severe disease expression, as is the case in patients who also have de novo mutations in other cardiac sarcomeric contractile protein genes. ${ }^{23}$ Most of the family members who carried the Glu99Lys mutation were reported to have symptoms of disease. Two had experienced ventricular arrhythmia, of which one had been resuscitated from cardiac arrest (no age reported). The predominant finding on echocardiograms in this family was that most of the affected members had apical hypertrophy of the myocardium.

The heterogeneous disease expression associated with ACTC mutations in this study accords well with the results of recent studies that investigated the clinical expression of mutations in other genes associated with HCM. $^{23}$ Environmental factors and individual genetic backgrounds are likely to modify the phenotype of mutation carriers. ${ }^{24}$

\section{Conclusion}

Mutations of the ACTC gene in patients with HCM are rare, and no gene specific phenotype is apparent. Localisation of ACTC mutations in conserved and functionally important regions of the gene substantiate the hypothesis that ACTC mutations in patients with HCM affect sarcomere contraction, whereas ACTC mutations in patients with DCM affect force transmission from the sarcomere to the surrounding syncytium.

\section{ACKNOWLEDGEMENTS}

This work was supported by Faculty of Health Sciences, University of Aarhus; Danish Heart Foundation; Danish Medical Research Council; Novo Nordic Foundation; Institute of Experimental Clinical Research, University of Aarhus; Hertz Foundation; Max Delbrück Center for Molecular Medicine, and Deutsche Forschungsgemeinschaft (OS 134/ 3-1).

\section{Authors' affiliations}

J Mogensen, I C Klausen, H Egeblad, Department of Cardiology, Skejby University Hospital, Brendstrupgaardsvej, DK-8200 Aarhus N, Denmark J Mogensen, P Bross, N Gregersen, Research Unit for Molecular Medicine, Skejby University Hospital, Brendstrupgaardsvej, DK-8200 Aarhus N, Denmark
A Perrot, K J Osterziel, Charité/Franz-Volhard-Klinik, Max Delbrück Center for Molecular Medicine, 13125 Berlin, Germany

P S Andersen, M Christiansen, Department of Clinical Biochemistry, Statens Serum Institut Copenhagen, DK-2300 Copenhagen S, Denmark O Havndrup, H Bundgaard, Department of Medicine B 2141, Heart Center, University of Copenhagen, DK-2100 Copenhagen $\varnothing$, Denmark G Haltern, H Lapp, Heart Center Wuppertal, University Witten/ Herdecke, 42283 Wuppertal, Germany

P Reinecke, Institute of Pathology, Heinrich Heine University, 40225 Düsseldorf, Germany

A D Børglum, Danish Center for Human Genome Research, Institute of Human Genetics, Bartholin Building, University of Aarhus, DK-8000 Aarhus C, Denmark

Conflicts of interest: None declared.

Correspondence to: Dr J Mogensen, Department of Cardiology, Skejby University Hospital, Brendstrupgaardsvej, DK-8200 Aarhus N,

Denmark; jens.mogensen@dadlnet.dk

Received 11 May 2003

Accepted 10 June 2003

\section{REFERENCES}

1 Maron BJ. Hypertrophic cardiomyopathy. Lancet 1997;350:127-33.

2 Bonne G, Carrier L, Richard P, Hainque B, Schwartz K. Familial hypertrophic cardiomyopathy: from mutations to functional defects. Circ Res 1998;83:580-93.

3 Mogensen J, Klausen IC, Pedersen AK, Egeblad H, Bross P, Kruse TA, Gregersen N, Hansen PS, Baandrup U, Borglum AD. Alpha-cardiac actin is a novel disease gene in familial hypertrophic cardiomyopathy. J Clin Invest 1999; 103:R39-43.

4 Kimura A, Harada H, Park JE, Nishi H, Satoh M, Takahashi M, Hiroi S, Sasaoka T, Ohbuchi N, Nakamura T, Koyanagi T, Hwang TH, Choo JA Chung KS, Hasegawa A, Nagai R, Okazaki O, Nakamura H, Matsuzaki M, Sakamoto T, Toshima H, Koga Y, Imaizumi T, Sasazuki T. Mutations in the cardiac troponin I gene associated with hypertrophic cardiomyopathy. Nat Genet 1997; 16:379-82.

5 Blair E, Redwood C, Ashrafian H, Oliveira M, Broxholme J, Kerr B, Salmon A, Ostman-Smith I, Watkins H. Mutations in the gamma(2) subunit of AMPactivated protein kinase cause familial hypertrophic cardiomyopathy: evidence for the central role of energy compromise in disease pathogenesis. Hum Mol Genet 2001; 10:1215-20.

6 Arad M, Benson DW, Perez-Atayde AR, McKenna WJ, Sparks EA, Kanter RJ, McGarry K, Seidman JG, Seidman CE. Constitutively active AMP kinase mutations cause glycogen storage disease mimicking hypertrophic cardiomyopathy. J Clin Invest 2002;109:357-62.

7 Geier C, Perrot A, Ozcelik C, Binner P, Counsell D, Hoffmann K, Pilz B, Martiniak Y, Gehmlich K, van der Ven PF, Furst DO, Vornwald A, von HE, Nurnberg P, Scheffold T, Dietz R, Osterziel KJ. Mutations in the human muscle LIM protein gene in families with hypertrophic cardiomyopathy. Circulation 2003;107:1390-5

8 Olson TM, Michels VV, Thibodeau SN, Tai YS, Keating MT. Actin mutations in dilated cardiomyopathy, a heritable form of heart failure. Science 1998;280:750-2.

9 Charron P, Dubourg O, Desnos M, Isnard R, Hagege A, Millaire A, Carrier L, Bonne G, Tesson F, Richard P, Bouhour JB, Schwartz K, Komajda M. Diagnostic value of electrocardiography and echocardiography for familia hypertrophic cardiomyopathy in a genotyped adult population. Circulation 1997;96:214-9.

10 McKenna WJ, Spirito $P$, Desnos M, Dubourg O, Komajda M. Experience from clinical genetics in hypertrophic cardiomyopathy: proposal for new diagnostic criteria in adult members of affected families. Heart 1997;77:130-2.

11 Bundgaard H, Havndrup O, Andersen PS, Larsen LA, Brandt NJ, Vuust J, Kjeldsen K, Christiansen M. Familial hypertrophic cardiomyopathy associated with a novel missense mutation affecting the ATP-binding region of the cardiac beta-myosin heavy chain. J Mol Cell Cardiol 1999;31:745-50. 
12 Protein Information Resource. Protein alignment database. Washington, DC: National Biomedical Research Foundation, 2000. http:// www.nbrf-georgetown.edu (accessed April 2000).

13 Mayosi BM, Khogali S, Zhang B, Watkins H. Cardiac and skeletal actin gene mutations are not a common cause of dilated cardiomyopathy. J Med Genet 1999;36:796-7.

14 Takai E, Akita H, Shiga N, Kanazawa K, Yamada S, Terashima M, Matsuda Y, Iwai C, Kawai K, Yokota Y, Yokoyama M. Mutational analysis of the cardiac actin gene in familial and sporadic dilated cardiomyopathy. Am J Med Genet 1999;86:325-7.

15 Baandrup U, Olsen EG. Critical analysis of endomyocardial biopsies from patients suspected of having cardiomyopathy. I: Morphological and morphometric aspects, $\mathrm{Br}$ Heart J 1981;45:475-86.

16 Kumar A, Crawford K, Close L, Madison M, Lorenz J, Doetschman T, Pawlowski S, Duffy J, Neumann J, Robbins J, Boivin GP, O'Toole BA', Lessard JL. Rescue of cardiac alpha-actin-deficient mice by enteric smooth muscle gamma-actin. Proc Natl Acad Sci USA 1997;94:4406-11.

17 Kabsch W, Mannherz HG, Suck D, Pai EF, Holmes KC. Atomic structure of the actin:DNase I complex. Nature 1990;347:37-44.

18 Rayment I, Holden HM, Whittaker M, Yohn CB, Lorenz M, Holmes KC Milligan RA. Structure of the actin-myosin complex and its implications for muscle contraction. Science 1993;261:58-65

19 Kabsch W, Holmes KC. The actin fold. FASEB J 1995;9:167-74.
20 Olson TM, Doan TP, Kishimoto NY, Whitby FG, Ackerman MJ, Fananapazir L. Inherited and de novo mutations in the cardiac actin gene cause hypertrophic cardiomyopathy. J Mol Cell Cardiol 2000;32:1687-94.

21 Karkkainen S, Peuhkurinen K, Jaaskelainen P, Miettinen R, Karkkainen P, Kuusisto J, Laakso M. No variants in the cardiac actin gene in Finnish patients with dilated or hypertrophic cardiomyopathy. Am Heart J 2002;143:E6.

22 Richard P, Charron P, Carrier L, Ledeuil C, Cheav T, Pichereau C, Benaiche A, Isnard R, Dubourg O, Burban M, Gueffet JP, Millaire A, Desnos M, Schwartz K, Hainque B, Komajda M. Hypertrophic cardiomyopathy: distribution of disease genes, spectrum of mutations, and implications for a molecular diagnosis strategy. Circulation 2003;107:2227-32.

23 Mogensen J, Bahl A, Kubo T, Elanko N, Taylor R, McKenna WJ. Comparison of fluorescent SSCP and denaturing HPLC analysis with direct sequencing for mutation screening in hypertrophic cardiomyopathy. J Med Genet 2003;40:E59.

24 Mogensen J, Kubo T, Duque M, Uribe W, Shaw A, Murphy R, Gimeno JR, Elliott $P, M c K e n n a$ WJ. Idiopathic restrictive cardiomyopathy is part of the clinical expression of cardiac troponin I mutations. J Clin Invest 2003;111:209-16

25 Semsarian C, Healey MJ, Fatkin D, Giewat M, Duffy C, Seidman CE, Seidman JG. A polymorphic modifier gene alters the hypertrophic response in a murine model of familial hypertrophic cardiomyopathy. J Mol Cell Cardio $2001 ; 33: 2055-60$. 